$45 \mid 2010$

Langue française, identité(s) et école(s) : le cas de la minorité catholique au Levant (milieu XIX ${ }^{\mathrm{e}}-\mathrm{XX}^{\mathrm{e}}$

siècles). Représentations identitaires et apprentissage des langues : Europe, bassin méditerranéen ( $\left.\mathrm{XV}\right|^{\mathrm{e}}-\mathrm{XX}{ }^{\mathrm{e}}$ siècles)

\title{
Italie, 1830-1914. La mise en scène de l'autre et la naissance de l'identité nationale dans les manuels scolaires pour l'enseignement/apprentissage du français
}

Nadia Minerva

\section{OpenEdition}

Édition électronique

URL : https://journals.openedition.org/dhfles/2462

DOI : $10.4000 /$ dhfles.2462

ISSN : 2221-4038

Éditeur

Société Internationale pour l'Histoire du Français Langue Étrangère ou Seconde

Édition imprimée

Date de publication : 1 juin 2010

Pagination : 157-175

ISSN : 0992-7654

Référence électronique

Nadia Minerva, «Italie, 1830-1914. La mise en scène de l'autre et la naissance de l'identité nationale dans les manuels scolaires pour l'enseignement/apprentissage du français », Documents pour l'histoire du français langue étrangère ou seconde [En ligne], 45 | 2010, mis en ligne le 01 février 2014, consulté le 27 mai 2021. URL : http://journals.openedition.org/dhfles/2462 ; DOl : https://doi.org/10.4000/dhfles. 2462

Ce document a été généré automatiquement le 27 mai 2021

(c) SIHFLES 


\title{
Italie, 1830-1914. La mise en scène de l'autre et la naissance de l'identité nationale dans les manuels scolaires pour l'enseignement/ apprentissage du français
}

\author{
Nadia Minerva
}

Bien souvent, pour dissiper les préjugés et les haines il suffit de se connaître. (Toldo \& Guichard

$1906: 59)$

1 Mon étude, qui concerne l'enseignement de la culture française en Italie, se focalise sur quelques livres de lecture ou des anthologies parus en Italie entre 1830 et $1914^{1}$. Elle vise à recenser les contenus culturels de la littérature didactique parue à cette époque et à faire émerger l'impact de certains événements, relevant de la politique étrangère, de la politique culturelle et éducative, de la politique économique, sur les manuels conçus pour l'enseignement du français.

2 Pour notre propos, cette période peut être divisée en trois étapes: 1830-1890, 1891-1900, 1901-1914, en raison d'une sensibilité diverse de la part des auteurs des manuels, des pédagogues et des législateurs à l'égard de la culture française. En effet, ce ne sont que la dernière décennie du XIX ${ }^{\mathrm{e}}$ siècle et le début du XX $\mathrm{XX}^{\mathrm{e}}$ qui nous font assister à la naissance de l'enseignement/apprentissage de la culture du pays dont on apprend la langue. L'enseignement du français dans l'école italienne n'a produit que fort tard la conscience - chez les maîtres et chez les auteurs de manuels - d'un impératif didactique disciplinaire : faire connaître le peuple qui parle cette langue. À un univers de référence neutre on substituera - principalement dans les manuels s'inspirant de la méthode directe - un univers culturellement connoté. 


\section{$1830-1890$}

3 Jusqu'aux années 1890, la France est la grande absente des manuels de français. Il n'y figure que sa littérature, et l'enseignement de la littérature n'est dispensé que dans les classes terminales de l'instruction secondaire - au cours de la sixième année d'apprentissage du français. Quant aux pages d'auteurs et aux textes fabriqués proposés dans les autres classes, la plupart des auteurs ne misent que sur leur exploitation linguistique, ne manifestant aucun intérêt pour la dimension culturelle de l'apprentissage d'une langue étrangère. Dans ces manuels, il serait vain de chercher des contenus civilisationnels ayant trait à la France. Ce qui intéresse les maîtres italiens, c'est uniquement de fournir des modèles linguistiques. Pour illustrer le but principal de la sélection des pages de lecture, on peut citer deux titres parlants: Modèles de style à l'usage de la jeunesse (1841) et Exercices de mémoire et de style (Belèze 1859) ${ }^{2}$, ou écouter les propres mots d'un auteur tel que Charles Musslin qui, présentant son recueil, professe avoir réuni « tout ce que la langue française peut avoir de difficultés quant au style et à la variété des expressions $»^{3}$. D’ailleurs, quelques années plus tard, lors de la naissance de l'école d'État, les programmes ministériels préciseront que les lectures servent à repérer « l'application pratique des règles » et à faire acquérir « la partie matérielle de la langue qui se compose de vocables, d'expressions et de locutions $»^{4}$ (je traduis).

4 Quant aux contenus des ouvrages, ces mêmes programmes stipulent qu'on présente des auteurs modernes ayant écrit sur les arts, l'industrie, le commerce, les notions utiles, les voyages, les vertus laborieuses, etc., mais ces contenus servent avant tout à fournir des modèles idéologiques et éthiques. Les textes - poèmes, scènes de théâtre, histoire, sciences naturelles, récits de voyages, vies exemplaires, littérature pour la jeunesse véhiculent en fait une leçon morale, religieuse, historique ou scientifique. Les manuels de français (et, plus généralement, tous les manuels de l'époque) ont en effet trois objectifs culturels : la moralisation, la professionnalisation, la formation patriotique.

\section{Éducation religieuse et moralisation}

5 Le but moral est évidemment toujours présent (tous les manuels du XIX ${ }^{e}$ siècle, dans tous les pays, se ressemblent) : former l'esprit et le cœur des enfants et des adolescents par l'exemple de principes moraux inébranlables.

6 Salvatore Torretti propose un texte pour la lecture à haute voix. Pour que le «lecteur encore novice» puisse concentrer toute son attention sur l'exactitude de la prononciation, l'auteur offre des textes connus «par cœur", dit-il $(1836: 5)^{5}$, de telle façon qu'aucun obstacle ne s'interpose à la compréhension : l'histoire sacrée, l'histoire romaine et la vie de Jésus-Christ. Comme le relève Carla Pellandra, « le français joue ici le rôle d'une langue qui véhicule des contenus faisant partie d'un patrimoine culturel déjà acquis par ces élèves, l'antiquité classique et la religion. » (1993 : 33-34)

7 En 1834, le même auteur publie des Récréations du cœur et de l'esprit, dont les sources sont la Morale en action, l'Encyclopédie comique, le Dictionnaire des anecdotes et quelques auteurs tels que La Fontaine et Chateaubriand. Il donne les raisons de ces choix : « un style pur et correct, une morale pleine d'intérêt, beaucoup de gaieté, sans indécence... » (Préface: V-VII). Dans l'apprentissage, cette anthologie devrait suivre - aux vues de son compilateur - le Manuel de lecture. 
Dans la même lignée se placent les Premières lectures françaises (1838) d'Alexis Bochet où le choix des auteurs et des textes est encore une fois animé par des soucis purement linguistiques, religieux et moraux (entre autres, y figurent une Petite Histoire Sainte, la Rhétorique des demoiselles et l'immanquable Morale en action). Comme l'indique le soustitre, à travers des morceaux choisis, Bochet se propose d'enseigner la langue parlée et la grammaire : il ne suffit que de les recopier, de les apprendre par cœur et de répondre aux questions grammaticales qui couronnent le livre.

Citons encore un Cours de lectures françaises anonyme (1841), qui propose des morceaux de sujet classique («Le lion reconnaissant », «Situation de la grotte de Calypso »... ), des épisodes d'héroïsme, la géographie ("La Norvège »), l'histoire ("L'Algérien », concernant le bombardement d'Alger de la part de la flotte de Louis XIV), des biographies (Dante, Socrate...), des pages «morales» et "philosophiques» («Les généreux », « De l'homme »...).

Inutile de s'attarder en essayant de trouver des traits se rapportant à la culture française. La monotonie de ces livres de lecture est frappante: toujours les mêmes sujets et les mêmes objectifs. Il suffit de parcourir les répertoires dressés par l'équipe italienne et de relever les titres d'A. Boniface, C. S. Martin, Giuseppe Asti, Jean-Auguste Fornier... ou de jeter le dernier coup d'œil aux Elementi di lettura de Vincenzo Leitenitz, qui proposent des textes en prose sur des caractères et des modèles de comportement moral et social et qui réunissent des poèmes "pour exercice de mémoire et de déclamation. Sujets moraux et religieux. Fables et allégories » $(1859: 39-90)$.

\section{Le français pour les filles}

11 L'éducation féminine, comme on pouvait s'y attendre, renchérit la leçon morale et minimise à la fois les connaissances utiles, les limitant au strict domaine familial : les savoirs des femmes ne leur serviront qu'à éduquer leurs enfants. Le précepteur français des petites demoiselles (Musslin 1856) affirme offrir des lectures plus attrayantes que d'autres manuels se bornant à une "répétition de l'histoire sacrée » (Musslin vise-t-il Torretti ? ${ }^{6}$. Des prières, des anecdotes morales et les premiers éléments d'arithmétique sont tout ce qui sert à la formation d'une parfaite demoiselle dont l'avenir ne doit pas réserver de surprises: les leçons de Molière, Fénelon et Rousseau sur les femmes savantes ont trouvé en Italie un terrain fertile. C'est toujours pour les filles que Cecilia Cressoni, institutrice, a réuni des notions conformes à l'esprit de ses élèves, pour lesquelles le français est utile, mais non indispensable! Plus utile que le français semble être l'italien, d'où ses Esercizi di lettura francese-italiana (1859) qui entraînent à la lecture de courts extraits donnés dans les deux langues en regard. Citons encore le Second livre de lectures françaises à l'usage des écoles communales et des institutions de demoiselles (Rossari 1860) qui contient, divisées en six chapitres, de simples notions de " Religion et morale, Hygiène, Cosmographie et géographie, Industrie, Arithmétique, Géométrie ", suivies d'une anthologie proposant les mêmes sujets.

On ne s'étonne pas si Louis Brianzi, auteur d'un manuel de lecture destiné aux filles (L'Abeille, 1872) couronné à l'exposition nationale de Gênes de 1884, affirme en suivant ses prédécesseurs que la langue française ne doit pas être "un vain ornement» de l'esprit, mais constituer "une occasion de plus d'inculquer des principes salutaires ", grâce à des textes édifiants ou à des notions utiles aux futures épouses et mères de famille : la religion, l'hygiène, l'économie domestique. 


\section{La professionnalisation} lecture qui se concentrent sur des notions utiles, des textes instructifs concernant les découvertes géographiques et scientifiques, les acquisitions de la technique, l'histoire naturelle, l'astronomie, la météorologie, l'anatomie et les biographies des savants: celles de Benjamin Franklin et Humphy Davy, de Galilée et Newton ne manquent jamais. Une remarque curieuse: dans tous ces manuels, on peut lire une page sur le café !

Citons, pour tous, la Nomenclature en action où Ghiotti et Dogliani (1886) ne font que moderniser le vocabulaire des vieilles grammaires dont on garde l'organisation descendant de Dieu aux aspects de la vie quotidienne. Chaque nomenclature est suivie d'entretiens entre le maître et ses élèves sur l'univers et le globe terrestre, occasion pour rappeler les noms des planètes et des points cardinaux, d'expliquer ce que sont les pôles et l'équateur, la longitude et la latitude, les océans et les continents. On y distingue les collines des vallées, les lacs des étangs, le golfe de la baie... Ensuite, on passe à l'illustration des lois physiques, aux propriétés des corps, aux minéraux... jusqu'aux arts et métiers en passant par la ville et la maison. Les listes des mots recensés sont interminables (dans la section "Animaux» on compte plus de 250 termes), boulimie lexicale qui dénote une tension encyclopédique décidément déplacée : les destinataires sont les élèves de l'école technique (11-14 ans). La méthode est rébarbative: les causeries entre le professeur et les élèves sont de véritables supplices. «Que fait-on avec l'acier? », «Que fait-on avec le cuivre? " « Que fait-on en argent?» Les élèves répondent promptement et correctement, le français ne servant qu'à nommer des contenus connus.

\section{La formation patriotique}

Les Letture graduate francesi de Brian-Rey et Spedini (1868) offrent un bel exemple de cette indifférence à l'égard de la transmission de contenus culturels français. Il faut admettre que dans ce recueil on peut lire quelques fables de La Fontaine, des extraits du Discours des morts de Fénelon, des pages de Buffon, mais ce qui intéresse, ce sont plutôt les Italiens héroïques, parmi lesquels abondent les enfants. On est en Italie, observent les auteurs, on s'adresse à de jeunes Italiens, donc on doit présenter les hommes qui ont illustré leur pays ${ }^{7}$ : Cincinnatus, César, Dante, Michel-Ange, Galilée, Le Tasse, Goldoni, Pietro Micca... et des aperçus sur «notre chère Italie »- le «jardin de l'Europe " aux beautés incomparables - fraîchement unifiée, des textes illustrant sa langue et sa littérature. Toute la rhétorique bourgeoise est à l'œuvre pour former le nouveau citoyen de la nouvelle nation. "L'Italia è fatta, ora bisogna fare gli italiani " (devise archiconnue de Massimo d'Azeglio) : une fois accomplie l'unité politique, il y a à résoudre le problème, bien plus difficile, de l'unification civile des Italiens. L'école est forcément engagée dans cette entreprise prioritaire : il fallait «faire les Italiens » à travers la mémoire d'événements historiques glorieux. "Tout le processus de formation identitaire a consisté à déterminer le patrimoine de chaque nation et à en diffuser le culte ", observe Anne-Marie Thiesse (1999: 12). Aux manuels la tâche de diffuser ce culte, de forger la conscience nationale, l'identité collective (souvent avec des pointes de gallophobie). La giovane nazione (l'unification de l'Italie est toute récente) 
doit construire l'identité nationale, l'esprit italien, d'où le patriotisme qui caractérise toute la production scolaire de l'époque.

16 C'est donc l'Italie, avec sa géographie, son histoire, ses gloires passées et présentes qui occupe toute la scène. La culture scolaire du temps est bourrée d'histoire grecque et romaine, de mythologie, d'histoire sacrée, d'éloges de notre langue et littérature. Les études classiques sont les garants des valeurs de la tradition et, pour un État qui vient de naître, s'impose une politique culturelle visant à nouer le lien avec ses propres racines, à savoir le monde classique, notamment, comme le remarque Galli della Loggia, l'empire romain qui peut fournir un passé historique et mythique commun à tous les Italiens (1998: 31 et suiv.).

17 Et, qui plus est, les partisans des langues modernes font figure d'ennemis de la culture nationale, des traditions, donc de la patrie. D'ailleurs, comment présenter en classe la culture française? La littérature de France, si célébrée, est immorale, elle fomente la partialité politique et religieuse.

Non pas une politique culturelle du rapprochement, mais une stratégie de mise à distance. Cette attitude traduit un parti pris de politique culturelle central dans ce moment historique particulier.

\section{Italie et France en regard : la méthode comparative}

Une médiation est-elle possible ? L'anthologie de Zuliani (Raccolta di racconti, descrizioni, lettere e dialoghi) sélectionne - dans les pages des « meilleurs écrivains français »!!! - 30 morceaux du Télémaque et 30 des Fiancés d'Alessandro Manzoni pour l'exercice de la traduction (version et thème), dans le but de permettre à l'élève de se familiariser avec le style des classiques, de s'approprier l'« esprit » de la langue française et de mesurer la «distance» avec sa langue maternelle $(1861: 116)^{8}$. On prend conscience de sa propre langue et de sa propre culture par le biais de la confrontation avec une autre langue et une autre culture.

Le souci de mettre l'enseignement de la langue française à contribution pour créer une conscience nationale est évident dans les programmes ministériels qui recommandent que l'italien soit la base de l'enseignement du français; ils préconisent l'emploi d'une méthode comparative afin que l'enseignement de la langue étrangère puisse servir aussi pour mieux connaître la langue nationale qui était d'ailleurs assez rarement, à l'époque, la langue maternelle des élèves : l'Italie était et restera encore longtemps un pays dialectophone. Le pilier de plusieurs manuels est en effet la comparaison entre la langue maternelle et la langue cible. Le point de départ sont l'italien et l'Italie : on doit exploiter la parenté des deux langues. La méthode doit être adaptée à notre nature, à nos besoins, à nos moyens, nous explique Candido Ghiotti dans sa Grammatica ragionata della lingua francese. Nuovo corso di lezioni teorico-pratiche dettate col confronto della lingua italiana (1868). Fidèle à sa méthode comparative, Ghiotti présente sa Nomenclature en action (voir supra) sur deux colonnes où l'italien précède le français.

\section{$1891-1900$}

Dans ses écrits pédagogiques, Pasquale Villari interprète un mouvement de valorisation de l'autre qui va s'affirmer dans ces années, quand il voit, dans la langue, «tous les 
affects, toutes les pensées, l'histoire, l'âme et la vie morale d'un peuple $»^{9}$. Une langue est un monde moral, « une culture tout entière ». professeurs... Il s'agit d'un recueil de dialogues dans la capitale à partir de l'arrivée de Gustave Argenti, professeur de droit civil en congé «venant à Paris employer [ses] loisirs». Son interlocuteur est Charles Roland, un journaliste qui se dit charmé de pouvoir le "parisianiser » $(1900: 1)$. La visite commence par la topo-graphie de la ville. Après les monuments et les lieux caractéristiques, on se déplace en banlieue, on se promène sur les Grands Boulevards pour un apéritif, aux Halles pour assister à la vie frénétique du marché, on visite les grands magasins du Bon Marché, on jette un coup d'œil à la foire aux pains d'épices, on apprend l'argot théâtral, on assiste à une séance à la Chambre, à une réception à l'Académie française, on va à un vernissage... et, puisque le mois de congé passe vite, il ne reste que le temps pour assister à une exécution capitale. Quels sont les objectifs de ces causeries? Se former à la conversation française, acquérir des notions utiles sur la vie, les mœurs, les aspects les plus remarquables de la culture française en vue d'un séjour à l'étranger («Prefazione»: VII).

Cet enthousiasme pour la culture française ne fait pas l'unanimité, ce qui reflète les rapports sociopolitiques entre les deux sœurs latines, troublés par divers facteurs ${ }^{10}$. Sans remonter aux guerres de l'indépendance - à la question des provinces italiennes annexées par la France - qui font enregistrer une alternance de moments propices avec des phases de véritable crise diplomatique, il suffit de se focaliser sur les hostilités de la période 1880-1910 qui commence par les brouilles liées à la présence de la France en Tunisie où était installée depuis longtemps une colonie italienne nombreuse et prospère (1881). À cause de la proximité de la Tunisie des côtes de la Sicile, cette présence sera bientôt interprétée par l'opinion comme une menace contre l'intégrité de la péninsule. Dans les années suivantes, l'Italie se rapproche de plus en plus de l'Allemagne et c'est dans cette atmosphère qu'éclatent la guerre des douanes amorcée 
par le protectionnisme français et les désordres d'Aigues-Mortes ${ }^{11}$ qui font frémir l'opinion italienne. Avec la renonciation de l'Italie à ses prétentions sur la Tunisie (1896), les accords sur la politique coloniale des deux pays et les nouveaux traités commerciaux de 1898, la France sera enfin saluée comme une amie et une alliée (Ragionieri 1975 : passim ; Carpentier / Lebrun 1998 : 384-388). L'impact de certains événements sur les contenus civilisationnels de l'enseignement du français est toujours inévitable.

Les contenus évoqués pour la période précédente font donc leur chemin dans plusieurs manuels qui ne se ressentent aucunement de la foulée novatrice, laquelle ne se manifeste d'ailleurs que timidement. Par exemple, dans les Letture francesi $(1897)^{12}$ de Giovanni Bonfiglio, la seule teinture de culture française sont les prénoms des héros et héroïnes fictifs : René, Émile, Eugénie, Lisette qui est, bien sûr, la servante de Madame. Le livre prévoit aussi des morceaux d'auteurs français (Dumas, Verne, Mérimée, Le Sage...) qui - à vrai dire - semblent choisis surtout pour leur caractère principalement extra-hexagonal : "Une diligence dans une gorge de la Sierra Nevada », "La Sibérie », «Une nuit d'été à Saint-Pétersbourg », L'Orient de Voltaire, la Suisse de Guillaume Tell et, l'auteur du manuel étant sicilien, la Sicile et ses mines de soufre.

En 1898, Emma Fresia - une disciple fidèle de Ghiotti et Dogliani (le livre est dédié à ce dernier) - essaie d'obtenir le succès de la Nomenclature en action avec ses Lectures françaises graduées où figurent les vocabulaires relatifs au corps humain, aux sens, aux périodes de la vie, à l'univers, etc., accompagnés de courts textes et d'une pléthore de questions: "Combien y-a-t-il de dizaines dans une centaine?», "Parlez de l'estomac.», «Qu'est-ce qui arrive quand l'homme vieillit?», «Dites-moi toutes les parties de la porte ». Encore des contenus utiles peut-être à la formation des élèves, mais ne leur donnant aucune idée de la culture française.

\section{$1901-1914$}

$28 \mathrm{Au}$ tournant du siècle, les contenus culturels de quelques manuels ont subi une véritable métamorphose. Comme le relève Carla Pellandra, nos manuels ne véhiculent la culture française qu'après la pénétration en Italie de la méthode directe (1993 : $32-38)^{13}$.

29 Avec la méthode directe, se fait jour, corollaire obligé, l'enseignement de la civilisation. L'enseignement d'une langue, langue avant tout parlée, se fait enseignement d'une société et de sa culture en tant que culture du quotidien, en accord avec la recherche d'authenticité et de la langue courante de la communication dans les situations de la vie de tous les jours.

Romeo Lovera, directeur du Bollettino di filologia moderna - une revue très militante née pour promouvoir la méthode directe - écrit en 1901 qu'on ne veut plus connaître seulement la langue étrangère, mais aussi les conditions du peuple qui la parle. On va le voir dans ses villes, on entre dans les maisons où il vit, on veut pénétrer son âme, connaître ses institutions, ses idéaux, bref, sa civilisation ${ }^{14}$. Le mot est enfin lancé !

31 Si Evelina Fiorentino proclame la mort de la gallophobie (1903: 283), c'est pourtant chez Vincenzo De Meo que nous trouvons l'application des idées de Lovera et une formulation assez proche de celle de son collègue : 
Le professeur se sert de la langue qu'il enseigne comme d'un moyen pour faire connaître à ses élèves la vie du pays étranger, à savoir : les principaux faits de son histoire civile, ses beautés naturelles et artistiques, ses inventions, ses industries, son commerce, ses institutions, ses us et coutumes, sa littérature, enfin toute manifestation intellectuelle qui contribue à mieux faire apprécier le génie de la nation étrangère. (1908: 2)

Son programme de présentation de la culture étrangère est ambitieux. Il n'omet rien pour que l'élève apprenne à connaître en profondeur et à apprécier l'altérité. Par la méthode directe, on tire les élèves de leur routine quotidienne et on leur donne «l'illusion et l'avantage du séjour à l'étranger » (ibid.). Ainsi - poursuit-il - « les jeunes gens après leur sortie définitive de l'école pourront vivre par des livres, des revues, des journaux la vie des pays éloignés, auxquels les attachent des liens de sympathie et d'intérêt ». De Meo propose donc un véritable apprentissage de la différence par une approche comparative et dialogique : à l'Italie et à Rome font pendant la France et Paris, à l'école italienne l'enseignement supérieur français.

Autre trait de modernité : les « leçons de choses ». En expliquant l'utilité de ses « leçons des choses et de langage », De Meo conteste la «méthode indirecte »: «ce n'est pas la langue artistique rare ou plus ou moins archaïque de la littérature qu'il faut d'abord étudier, mais la langue courante, c'est-à-dire celle des journaux, des revues, de la correspondance, de la conversation ». La langue parlée doit toujours précéder la langue écrite. L'attaque contre les livres de lecture ne proposant que des pages littéraires est sans réserves.

Dans cette pédagogie linguistique, l'objectif de la compétence communicative réétablit les liens entre une langue et sa culture en faisant émerger l'histoire sociale et la microhistoire individuelle.

Voilà comment la France entre enfin dans les manuels et comment les contenus culturels deviennent de plus en plus français.

Nous devons à Pietro Toldo et Léon Guichard deux livres de lecture : Letture francesi per le scuole medie d'Italia (1905) et Les premières pages de ma vie (1906). Dans le premier, ces deux auteurs suivent en gros les consignes habituelles concernant les textes utiles ayant trait aux sciences, aux découvertes scientifiques et géographiques, aux savants, aux explorateurs, à la manufacture des produits utilisés dans la vie quotidienne; ils utilisent des extraits d'ouvrages utilisés en France pour la même tranche d'âge ${ }^{15}$. Cependant, dans les textes fabriqués on peut dénicher la culture française : la mer décrite n'est pas la Méditerranée mais les plages de l'océan Atlantique, on y boit du champagne, au théâtre on joue la Dame aux camélias, les examens ont lieu à la Sorbonne, les facteurs parisiens sont "transportés à de grandes distances sur des voiturettes à moteur mécanique » (26). Une «Promenade à Paris » (47-64) complète ce tableau de la civilisation française.

Le deuxième livre de lecture, Les premières pages de $m a v^{16}{ }^{16}$, est bien plus explicite: Toldo et Guichard y proclament la " nécessité pour les deux sœurs latines de s'unir, de marcher la main dans la main [...]», d'être liées par un "sentiment de cordiale fraternité ", pour «le progrès des idées, des études, des sciences, de l'industrie et du commerce » (1906: 188). Dans leurs pages, ils atteignent cet objectif par l'intermédiaire du protagoniste, un adolescent de mère française et de père italien, qui assure le dialogue entre deux langues et deux cultures. Leur lieu de rencontre est le journal d'Henri écrivant en français sur ses expériences dans l'école italienne de la première 
décennie du $\mathrm{XX}^{\mathrm{e}}$ siècle et lors d'un voyage par mer dans la Méditerranée. Dans son journal, Henri établit un parallèle suivi en faisant alterner des pages sur la France et des pages sur l'Italie. Une pacification et une intercompréhension sont possibles: il suffit que les deux peuples oublient quelques épisodes de leur passé ; « il y en a tant que nous pouvons lire avec enthousiasme et qui nous poussent à nous estimer, à nous aimer!» (111). Tout un jeu d'interférences, d'influences réciproques, de correspondances se met en place. Des destinées qui se croisent, des esprits qui s'entrelacent : l'Italie peut trouver son identité dans cette respiration européenne et méditerranéenne. Ce n'est pas un hasard si Toldo méthodologue ( Per l'insegnamento delle lingue moderne ») appelle de ses vœux les échanges épistolaires entre les écoliers italiens et français, l'échange de livres, de journaux et d'idées, pour que les jeunes deviennent - grâce à une authentique formation interculturelle - des citoyens d'un plus vaste monde (1907: 82).

Mais comment rendre actifs cette connaissance et cet éclairage sur l'au-delà des Alpes pour parfaire l'identité italienne?

Un autre pas est franchi grâce à une image de l'Italie qui s'ouvre non seulement à la France mais au monde, qui cherche le dialogue interculturel, qui dissipe les préjugés et qui assume pleinement son rôle de pont idéal entre le Nord et le Sud. Une Italie qui

semble presque jetée dans la Méditerranée comme une longue digue qui réunirait les pays de l'Europe centrale aux rives septentrionales de l'Afrique. Tandis qu'elle est, par les Alpes, étroitement unie à la France, la Suisse, l'Allemagne et l'AutricheHongrie, la mer qui l'entoure la met en facile communication avec l'Espagne, l'Afrique septentrionale, la Grèce et l'Asie Mineure. (1906: 70) pour voir reconnaître officiellement le rôle de la langue, de la culture et de la littérature étrangères dans l'intériorisation de la culture nationale - trop repliée sur elle-même - et dans la formation des jeunes Italiens. La Commission, créée pour analyser l'état de l'école italienne et pour en projeter la réforme, exprime à l'égard des langues étrangères une vision qui n'est plus seulement instrumentale: dans les nouveaux cursus, à l'étude dans ces années, la culture des élèves sera renforcée par l'apprentissage des langues vivantes considérées non seulement comme « des parlers et des outils de communication", mais aussi comme "des moyens de connaissance ethnologique, historique et spirituelle des nations qui les parlent $»^{17}$.

41 Cependant, ce qui vient d'être présenté ne concerne pour longtemps encore qu'un nombre très limité de manuels : un seul exemple, le Point de départ (1903, réédité sans modifications en 1914) de Tito Zanardelli, où nous retrouvons - parmi des anecdotes concernant des personnages célèbres, des fables, des contes de fées, des apologues et des calembours - les habituelles leçons morales et religieuses : «Ne tourmentez jamais les animaux », « Si les hommes ne te voient pas, Dieu te voit »...

\section{Conclusion}

42 Les contenus culturels de l'enseignement linguistique acquièrent une valeur incontournable au moment où l'on rejette la conception exclusivement utilitaire de la langue. C'est grâce à cette nouvelle conscience, que ceux qui réfléchissent, à l'aube du $\mathrm{XX}^{\mathrm{e}}$ siècle, sur les fins de l'enseignement d'une langue étrangère s'insurgent contre le système des «frasette insulse » (des petites phrases bêtes) qui caractérisent les 
méthodes pratiques (Gherius 1911), pour démontrer que seulement les textes authentiques, portant sans équivoque la marque de la "francité », réalisent le double objectif de l'efficacité didactique et de la croissance culturelle de l'apprenant.

Les manuels de cette période nous font assister à la découverte d'un objectif d'éducation interculturelle qu'on atteint à travers des lectures ayant trait à la France et à sa culture. On n'a évidemment pas oublié la construction de l'identité nationale, mais on prend conscience que cette identité ne peut que sortir renforcée du dialogue enrichissant avec l'autre.

\section{BIBLIOGRAPHIE}

Manuels

BELÈZE, Guillaume (1959). Exercices de mémoire et de style mis à la portée des enfants [...]. D'après la $17^{\mathrm{e}}$ édition de Paris. Milan : Gnocchi.

BOCHET, Alexis (1838). Premières lectures françaises à l'usage des étrangers ou choix des narrations familières les plus propres à leur faciliter les moyens de parler promptement le français [...]. Venise : à la librairie du Gondolier.

BONFIGLIO, Giovanni (1897). Letture francesi scelte e annotate per uso delle scuole secondarie d'Italia. Caltanissetta : Riccioni, $9^{\text {e }}$ ed.

BRIAN-REY \& SPEDINI (1866). Letture graduate francesi. Firenze : Civelli.

BRIANZI, Louis (1872). L'Abeille. Livre de lecture avec notes italiennes pour les jeunes personnes. Milan : Chez l'Auteur.

Cours de lectures françaises à l'usage de la jeunesse [...] (1841). Mantoue : Foa frères éditeurs.

CRESSONI, Cecilia (1859). Esercizi di lettura francese-italiana ad uso delle giovinette. Brescia : presso l'Autrice.

DARCHINI, Gaetano (1894). L'utile et l'agréable. Livre de lecture pour les écoles secondaires [...]. Rome : Società Editrice Dante Alighieri.

DE MEO, Vincenzo (1915). Le français usuel enseigné par la méthode directe. Florence : Bemporad ; $1^{\text {ère }}$ éd. 1908.

FIORENTINO, Evelina (1903). Par l'image. Grammaire pour l'enseignement du français par la méthode directe [...]. Florence : Sansoni.

FRESIA, Emma (1898). Lectures françaises graduées à l'usage des maisons d'éducation, des écoles complémentaires et des écoles techniques. Turin : Paravia.

GHIOTTI, Candido (1868). Grammatica ragionata della lingua francese. Nuovo corso di lezioni teoricopratiche dettate col confronto della lingua italiana. Alessandria : Ragazzone.

GHIOTTI, Candido \& DOGLIANI, Giustino (1886). La nomenclature en action [...]. Turin : Petrini. 
LEITENITZ, Vincenzo (1845). Elementi di lettura francese ad uso delle scuole italiane [...]. Napoli : Stamperia e Cartiere del Fibreno.

LEITENITZ, Vincenzo (1875). Premières lectures : morale pratique et connaissances utiles. Naples : Presso l'Autore.

Modèles de style à l'usage de la jeunesse (1841). Palerme : Jean Pedone.

MUSSLIN, Charles (1854). Exercices supérieurs de lecture française dédiés à la jeunesse. Côme : Annibal Cressoni éditeur.

- (1856). Le précepteur français des petites demoiselles. Milan : François Colombo.

PESCHIER, A. \& BANDERET, P. (1900). Causeries parisiennes. Recueil de dialogues à l'usage des Italiens qui veulent se former à la conversation française. Milan : Treves.

ROSSARI, Charles-Henri (1860). Second livre de lectures françaises à l'usage des écoles communales et des institutions de demoiselles. Turin : Paravia.

TOLDO, Pietro \& GUICHARD, Léon (1905). Letture francesi per le scuole medie d'Italia. $2^{\mathrm{e}}$ éd. Torino : Loescher.

- (1906). Les premières lectures de ma vie [...]. Turin : Loescher.

TORRETTI, Salvatore (1834). Récréations du cœur et de l'esprit ou Recueil de morceaux tirés de bons auteurs, à l'usage des maisons d'éducation et des personnes qui étudient la langue française [...]. Milan : Laurent Sonzogno.

- (1836). Manuel de lecture contenant l'abrégé de l'histoire sacrée, la vie de notre seigneur Jésus-Christ et celui de l'histoire romaine. Milan : Laurent Sonzogno.

ZANARDELLI, Tito (1903). Le point de départ. Libro di letture francesi scelte e graduate per gli alunni delle scuole secondarie.Milano-Palermo-Napoli : Remo Sandron.

Sources secondaires

AMANTE, Bruto (1880). Manuale di legislazione scolastica vigente ovvero raccolta di leggi, regolamenti, circolari e programmi sulla pubblica istruzione emessi dal 1860 a tutto il 1870 e coordinati alla legge fondamentale (Casati). Roma : Stamperia Reale.

CARPENTIER, Jean \& LEBRUN, François (éds) (1998). Histoire de la Méditerranée. Paris : Seuil.

GALLI DELLA LOGGIA, Ernesto (1998). L'identità italiana. Bologna : Il Mulino.

GHERIUS (1911). Come s'impara una lingua. Milano : La Casa d'Aldo Editrice.

LOVERA, Romeo (1901). «L'insegnamento delle lingue moderne », Bollettino di Filologia moderna, a. III, $\mathrm{n}^{\circ} 1$.

MARTINET, Gilles \& ROMANO, Sergio (2001). Un'amicizia difficile. Milano : Ponte alle Grazie.

MINERVA, Nadia (2002). « France/Italie : une identité d'emprunt ou une identité en partage? Manuels italiens du début du XX $\mathrm{XX}^{\mathrm{e}}$ siècle ", Documents pour l'histoire du français langue étrangère ou seconde, 28, 119-134.

MINERVA, Nadia (ed.) (2003). Insegnare il francese in Italia. Repertorio di manuali pubblicati dal 1861 al 1922. Bologna : CLUEB.

MINERVA, Nadia (2006). « Insegnare le lingue/culture ieri. L'Ottocento e il rinnovamento dell'insegnamento linguistico-culturale tra scienze umane e scienze sperimentali », in D. Londei, D. R. Miller, P. Puccini (ed.), Insegnare le lingue/culture oggi : il contributo dell'interdisciplinarità, Bologna : Asterisco, 35-53. 
- (2008). «Insegnamento e manualistica delle lingue straniere. Il francese tra i due secoli », in G. Chiosso (ed.), TESEO. Editori scolastico-educativi del primo Novecento, Milano : Editrice Bibliografica, XCVII-CXI.

- (2010). « Le français en Italie à l'aube du XX ${ }^{\mathrm{e}}$ siècle : école publique et université face aux défis d'un enseignement de qualité ", in Marco Lombardo \& Raphaël Muller (ed.), La cultura francese in Italia all'inizio del XX secolo. L'Istituto francese di Firenze, Firenze : Olschki, 13-26.

MINERVA, Nadia \& PELLANDRA Carla (ed.) (1997). Insegnare il francese in Italia. Repertorio analitico di manuali pubblicati dal 1625 al 1860. Bologna : CLUEB.

MINISTERO DELLA PUBBLICA ISTRUZIONE (1909). Commissione Reale per l'ordinamento degli studi secondari in Italia. Relazione. Roma : Cecchini.

PARIS, Roberto (1975). Storia d'Italia Einaudi. Dall'Unità ad oggi : L'Italia fuori d'Italia, vol. 10e . Torino : Einaudi.

PELLANDRA, Carla (1993). «Que lisait-on dans les classes de français d'autrefois ? Les contenus culturels de quelques manuels pour l'enseignement du français publiés en Italie de 1846 à 1908 ", Documents pour l'histoire du français langue étrangère ou seconde, 12, 32-38.

- (1996). « Libri dimenticati: un testo scolastico di Pietro Toldo », in Miscellanea in onore di Liano Petroni : studi e ricerche sulle letterature di lingua francese. Bologna : CLUEB, 273-283.

RAGIONIERI, Ernesto (1975). Storia d'Italia Einaudi. Dall'Unità ad oggi : La storia politica e sociale dall'Unità al Fascismo, vol. 13' ${ }^{\mathrm{e}}$, Torino, Einaudi.

THIESSE, Anne-Marie (1999). La création des identités nationales. Europe XVIII ${ }^{e}-X X^{e}$ siècles. Paris : Seuil.

TOLDO, Pietro (1907). « Per l'insegnamento delle lingue moderne », Nuovi doveri, rivista quindicinale di problemi pedagogici, a. I, $\mathrm{n}^{\circ} 5,15$ giugno.

VILLARI, Pasquale (1891). Nuovi scritti pedagogici. Firenze : Sansoni.

\section{NOTES}

1. La date de 1830 a été choisie car les premiers livres de lecture publiés en Italie datent des années 30 du XIX siècle. Quant à celle de 1914, elle a été choisie parce que pendant la Grande Guerre on constate une baisse considérable de la parution de nouveaux titres. Voir Minerva / Pellandra éds. 1997 et Minerva éd. 2003.

2. Gnocchi, l'éditeur milanais de ces Exercices, propose un extrait succinct d'un volumineux ouvrage français de Guillaume Belèze, Exercices de mémoire et de style à la portée de la jeunesse, paru à Paris chez J. Delalain en 1842. Belèze est l'auteur de nombreux textes scolaires.

3. Musslin 1854 : «À la jeunesse ».

4. Les programmes cités figurent dans Amante 1880.

5. Manuel de lecture contenant l'abrégé de l'histoire sacrée, la vie de notre seigneur Jésus-Christ et celui de l'histoire romaine. La première édition repérée date de 1836, mais ce texte est cité dans la Préface d'une édition des Récréations parue deux ans plus tôt.

6. Dédicace à « Mes bonnes amies» $: 5$.

7. «Dovendo essere questa raccolta per i giovinetti italiani, ci è sembrato conve-niente che dell'Italia vi si parlasse e degli uomini che la fecero grande. »

8. D'ailleurs, déjà en 1845, dans l'anthologie de ses Elementi di lettura, Vincenzo Leitenitz avait sélectionné des pages de Cesare Cantù et de La Fontaine. Les Elementi di lettura ont connu 
plusieurs rééditions et adaptations, le maître napolitain étant actif sur le marché de la librairie jusqu'à la fin du siècle. Voir aussi ses Premières lectures: morale pratique et connaissances utiles de 1875, devenues, en 1879, Premières lectures : morale pratique ou les bons exemples précédés de préceptes et de conseils [...].

9. Villari 1891: 292 : «tutti gli affetti, tutti i pensieri, la storia, l'anima e la vita morale di un popolo. »

10. Voir Martinet \& Romano $2001: 13$ et suiv.

11. L'épisode sera rappelé comme le plus grand massacre d'immigrés de l'histoire de France. Sur l'émigration italienne en France, cf. Paris 1975 : 525 et suiv.

12. Ce manuel a connu un bon succès et une certaine longévité : la dernière édition que je connais date de 1935.

13. Voir aussi : Minerva 2002 ; Minerva 2006 ; Minerva 2008 ; Minerva 2010.

14. «Non si vuol più conoscere solamente l'idioma straniero, ma anche le condizioni in cui si trova il popolo di cui si studia la lingua. Lo si va a trovare nelle città e nelle case in cui vive, si vuol sapere in che modo pulsi la sua anima, quali siano le sue istituzioni, i suoi commerci, le sue industrie, i suoi ideali, in una parola, la sua civiltà. » (Lovera 1901 : 11)

15. Lectures pratiques destinées aux élèves des cours moyen et supérieur de Jost et Braeunig (Hachette, 1881), Notions élémentaires de sciences appliquées à l'agriculture et à l'hygiène de O. Pavette ( $36^{\mathrm{e}}$ éd., Belin, 1903), Lectures variées sur les sciences usuelles (12 éd., Belin, 1882) et Nouvelles leçons des choses sur l'industrie, l'agriculture, le commerce de P. Maigne (Belin, 1883), Biographies des hommes illustres de D. Blanchet (Belin, 1882).

16. Sur Pietro Toldo et sur ce livre, voir Pellandra 1996.

17. «[...] l'apprendimento delle lingue vive, considerate non solo come loquele e strumenti di comunicazione pratica, ma anche come diretti organi di conoscenza etnologica, storica e spirituale delle nazioni a cui appartengono. » (Ministero della Pubblica Istruzione 1909 : 355)

\section{RÉSUMÉS}

La présente étude vise à faire émerger l'impact de certains événements, relevant de la politique étrangère, de la politique culturelle et éducative, sur les contenus culturels de l'enseignement du français.

Les premières décennies qui suivent l'unification de l'Italie, et notamment le début du XX ${ }^{\mathrm{e}}$, siècle nous font assister à la naissance de l'enseignement / apprentissage de la culture du pays dont on étudie / apprend la langue. L'enseignement du français à l'école italienne n'a produit que fort tard la conscience - chez les maîtres et chez les auteurs de manuels - d'un impératif didactique disciplinaire : faire connaître le peuple qui parle cette langue. À un univers de référence neutre on substituera - principalement dans les manuels s'inspirant de la méthode directe - un univers culturellement connoté.

This study aims to show the impact of a number of events linked to external affairs, and cultural and educational policy, on the cultural content of French language teaching.

In the first decades following the unification of Italy, notably in the early 20th century, we can witness the birth of the teaching / learning of the culture of the country where the language is spoken. The teaching of French in the Italian schools was slow to produce a consciousness among teachers and the authors of textbooks - of the educational need to know the people who 
speak the language. A universe of neutral reference will be replaced - mainly in textbooks inspired by the direct method - by a universe with sharp cultural connotations.

INDEX

Mots-clés : début XXe siècle, enseignement culturel, identité nationale, Italie, manuels de français

Keywords : early 20th century Italy, French language textbooks, national identity, teaching of culture

\section{AUTEUR}

NADIA MINERVA

Université de Catane, Italie nadia.minerva@unibo.it 